\title{
Minimally invasive cardiac surgery: in the pursuit to treat more and hurt less
}

\author{
Dimos Karangelis ${ }^{1} \wedge$, Vasiliki Androutsopoulou ${ }^{1}$, Aphrodite Tzifa ${ }^{2,3}$, George Chalikias $^{4}$, \\ Dimitrios Tziakas ${ }^{4}$, Fotis Mitropoulos ${ }^{5}$, Dimitrios Mikroulis ${ }^{1}$
}

${ }^{1}$ Department of Cardiac Surgery, Democritus University of Thrace, University Hospital of Alexandroupolis, Alexandroupolis, Greece; ${ }^{2}$ Department of Congenital Cardiology, Mitera Hospital, Athens, Greece; ${ }^{3}$ School of Biomedical Engineering \& Imaging Sciences, King's College London, London, UK; ${ }^{4}$ Cardiology Department, Medical School, Democritus University of Thrace, Alexandroupolis, Greece; ${ }^{5}$ Department of Cardiac Surgery, Mitera Hospital, Athens, Greece

Correspondence to: Dimos Karangelis, MD, PhD. Department of Cardiac Surgery, Democritus University of Thrace, University Hospital of Alexandroupolis, Alexandroupolis, Greece. Email: dimoskaragel@yahoo.gr.

Comment on: Nellis JR, Daneshmand MA, Gaca JG, et al. A single center experience with minimally invasive approaches in congenital cardiac surgery. J Thorac Dis 2021;13:5818-25.

Submitted Sep 13, 2021. Accepted for publication Sep 30, 2021.

doi: $10.21037 /$ jtd-21-1498

View this article at: https://dx.doi.org/10.21037/jtd-21-1498

Traditional cardiac surgery has gone through extensive modifications and has been infused with significant new enhancements and innovations over the last decade. Currently, there is a continuous and increasing interest in developing smaller incisions and as such the conventional techniques are in competition with minimally invasive approaches. Both patients and a great majority of doctors perceive minimally invasive surgery as more appealing, because it is usually associated with less pain and lower risks.

It has been shown that compared to the traditional sternotomy, minimally invasive cardiac surgery (MICS), besides the obvious cosmetic benefits, has been associated with reduced intensive care unit (ICU) and hospital length of stay (LOS), lower use of blood products, less pain and a more expedited recovery (1).

Notwithstanding, these techniques require surgical experience and a certain skill set which is developed through a learning curve. Holzhey et al., in a cornerstone paper from Leipzig have methodically examined the learning curve of MICS (2). According to this group, there is a prolonged and steep learning curve, even in a center performing a large volume of minimally invasive operations. Furthermore, their results seemed to depend greatly on the primary surgeon, as different surgeons exhibited notable differences in the learning curve of minimally invasive surgery of the mitral valve (2).

Apart from the learning curve, the technical aspects and the complexity of MICS, other common drawbacks include longer duration cross clamp and bypass time, myocardial protection and de-airing manoeuvres (3).

Nevertheless, despite all these challenges, MICS in the adult population has produced advantageous outcomes $(4,5)$, and its use is progressively expanding. In fact, in Germany almost $50 \%$ of mitral valve surgery is undertaken in a minimally invasive fashion (3).

MICS in congenital heart disease (CHD) patients has followed that of the adult population. However, MICS in CHD is a totally different game despite the fact that many of its concepts follow the principles used in the adult population. These approaches in CHD patients have to overcome several other barriers besides the learning curve, such as patient size (in small pediatric patients), and limitations in manufacturing surgical instrumentation (6). As far as the learning curve in MICS-CHD patients is concerned, this is further amplified by the low volume of congenital cases.

Albeit all the hurdles, the interest in these alternative

^ ORCID: 0000-0001-7633-9949. 
approaches in CHD patients continues to grow and it is encouraging that more data come to light supporting the safety and the applicability of these techniques along with the comparable mortality, the expedited recovery and the reduced LOS.

Such an article we come across in the current issue of the journal by Nellis and coworkers (7). In this single institution retrospective review, the authors report on their initial experience from a 3-year program focused in MICS in CHD patients.

Although the patients' sample size was small (49 patients), they covered a wide range of procedures with an overall reasonable conversion rate (14\%). Anomalous aortic origin of coronary arteries (AAOCA) as well as higher $\mathrm{BMI}$ and weight were associated with increased risk for conversion to sternotomy.

AAOCA encompasses a wide spectrum of coronary anomalies and a variety of surgical techniques have been developed for its repair. It is somewhat expected that besides unroofing, many of the other proposed repaired techniques, for example coronary reimplantation or pulmonary translocation, would have a high degree of difficulty to be applied through a mini-incision due to their complexity. In the article of Nellis et al. (7), this justifies the relevant conversion rate $(36 \%)$ to the conventional method, as well as the continuous increase on the graphical representation of cardiopulmonary bypass time (CPB) for subsequent AAOCA procedures.

On the other hand, with respect to the weight-conversion correlation, the small sample size and the rest of the study's limitations i.e., retrospective nature and patient selection, hinder further substantial and generalized conclusions. Besides, in adult patients, there is not enough evidence to suggest that obesity and high BMI affect the conversion rate $(8,9)$.

Another very important aspect of this paper is the acknowledgment of the team's approach. Dissemination of the practice of MICS in CHD patients can be rather challenging. Therefore, a coordinated team-based approach along with meticulous preoperative planning and involvement of designated proctors are prerequisites for establishing a new MICS program.

There are also many other parameters to be considered in order to set up a workable, effective and sustainable minimally invasive program. Besides the proctorship, the technical challenges and the steep learning curves, appropriate selection of the initial cases is fundamental. Avoidance of high-risk patients with multiple comorbidities or very complex procedures will ensure patient safety and keep complication and conversion rates to minimum. Surgeons need to be mindful that in these initial stages complications rates tend to be higher.

Additionally, a meaningful point that needs to be highlighted is that in congenital heart surgery it has been shown that there is a definitive risk reduction of mortality when patients are shifted from low to high-volume hospitals. Regionalization of care and the well-established relationship of better outcomes at higher volume centers has been emphasized by several authors (10). Chang and colleagues reported a $24 \%$ relative reduction in mortality that theoretically might have occurred if patients were shifted from low- to high-volume hospitals (11). This association between higher hospital volumes and better patient outcomes has been mirrored in the paper by Austin et al. in their recent analysis (12). Notably, the authors describe that an overall $26 \%$ reduction in observed deaths theoretically might have been prevented if higher-risk operations in CHD patients were to be performed in high volume hospitals (12).

Moreover, other studies have defined that an annual case volume of $>300$ index cases per year is a level above which the survival in CHD patients is optimized (13). Consequently, MICS in CHD should also follow the same principle.

MICS in CHD patients is here to stay, not only for aesthetic reasons. It is beyond any doubt that it potentially ameliorates the psychological impact that sternotomy incisions may induce. It will also stay for functional reasons, as it minimizes surgical trauma and pain, reduces the usage of blood products and shortens the recovery period. This latter effect however, is more profound in the adult population and less evident in children $(14,15)$.

Currently an increasing number of procedures are performed through a minimal invasive approach. This spectrum of diseases ranges from corrections of simple defects such as atrial septal defects (ASDs) and ventricular septal defects (VSDs), to tetralogy of Fallot repair and mitral valve repair, further incorporating repairs of atrioventricular septal defect and isolated pulmonary stenosis, extra-cardiac Fontan, and ventricular assist device placement (6,16-19). The minimal access approaches that have been described to address these pathologies reveal a wide surgical armamentarium. This includes upper or lower mini-sternotomy, submammary and posterior thoracotomy incision, axillary incisions and incisions used in roboticassisted procedures (6,16-19). Additionally, it extends to video-assisted thoracoscopic surgical (VATS) treatment of 
vascular rings, ligation of patent ductus arteriosus (PDA) and sew on of epicardial leads (6).

Most of these though have exhibited an array of limitations. Partial sternotomies leave the central residual scar, more visible in the upper sternotomy (20). Extensive thoracotomies may lead to scoliosis (21). In particular, anterior thoracotomies have been associated with asymmetric breast and pectoral muscle development and chest deformity $(21,22)$.

We have adopted the submammary thoracotomy along with the right mini-thoracotomy $\left(3^{\text {rd }}\right.$ intercostal) incision. Both of these have gratifying cosmetic results and provide a safe approach and for a wide variety of malformations such as ASDs, VSDs, and procedures on the aortic valve. As far as the submammary incision is concerned we find that retracting the breast tissue along with the pectoralis muscle avoids distortion and mal-development of the breast. Especially in female patients in prepubescent age the incision is done below the future development of the breast tissue and the key is to gain access from a higher intercostal space.

The traditional sternotomy scar may induce a significant adverse psychological impact and in rare cases even has consequences to the future social life of children or young adults. Bleiziffer et al. in their analysis demonstrated that $27 \%$ of the patients reported impairment of self-confidence through median sternotomy in a 10 -year follow up (22). More recently, Yan and colleagues showed that $35 \%$ of patients and their families reported that the cosmetic result of median sternotomy was unsatisfactory in the immediate postoperative period (23).

To date, more surgeons are demonstrating that MICS in the congenital population provides safe and cosmetically appealing outcomes $(16,17)$.

Several factors have propelled a significant growth of interest in MICS. Besides patient's aspiration for improved cosmesis, technical advances such as the intraoperative transesophageal echocardiography (TEE), utilization of smaller and better cannulas and catheters have also fueled this interest. Last but not least, a perpetual competition with the new percutaneous transcatheter interventional techniques has triggered surgeons' interest to adopt and innovate minimally invasive approaches and therefore has pushed the limits of MICS in CHD. The improving surgical outcomes in MICS are the resultant of these factors.

We should not forget that in the initial stages of a MICS program, it is vital to advance with caution, starting with simple cases and gradually expanding to the next stages as experience is growing. Conversion to full sternotomy in these early stages should not be regarded as defeat of the surgical team and core of discouragement. Surgeons need to focus on how to (I) reduce patient's surgical trauma, (II) improve functional results and cosmesis, (III) maintain a high standard of clinical outcomes and (IV) develop minimally invasive approaches for more complex lesions while overcoming their learning curves. Especially this last part is very important as there seems to be a turf war between MICS and catheter-based interventions because both of them have shown successful results in dealing the simple defects. MICS in CHD should not be confined only in cases where catheter interventions are not applicable or have a high failure rate, i.e., closure of VSDs (15) and the only way to do this is by expanding its current applications.

Practice of MICS in CHD patients must include a multidisciplinary team approach. MICS provides an excellent opportunity for a closer collaboration between cardiovascular surgeons and cardiac interventionists in order to provide hybrid strategies in the treatment of CHD, incorporating strengths of both disciplines (MICS and cardiac structural percutaneous interventions) (24). Areas for such collaborations have been reported in hypoplastic left heart syndrome, hemodynamically significant muscular VSD closure, pulmonary atresia with intact ventricular septum for right ventricular decompression, pulmonary valve replacement in dysfunctional right ventricular outflow tract, intra-operative pulmonary artery stenting and others (24).

Finally, careful preoperative planning is equally important with appraisal of long-term outcomes. Safety and efficacy along with patient satisfaction in the long run has yet to be evaluated. MICS may become the potential new standard of care for many congenital cardiac pathologies while the prominent unsightly midline scar will remain only for specific extremely complex repairs, redo procedures or as bail out.

\section{Acknowledgments}

Funding: None.

\section{Footnote}

Provenance and Peer Review: This article was commissioned by the editorial office, Fournal of Thoracic Disease. The article did not undergo external peer review.

Conflicts of Interest: All authors have completed the ICMJE 
uniform disclosure form (available at https://dx.doi. org/10.21037/jtd-21-1498). The authors have no conflicts of interest to declare.

Ethical Statement: The authors are accountable for all aspects of the work in ensuring that questions related to the accuracy or integrity of any part of the work are appropriately investigated and resolved.

Open Access Statement: This is an Open Access article distributed in accordance with the Creative Commons Attribution-NonCommercial-NoDerivs 4.0 International License (CC BY-NC-ND 4.0), which permits the noncommercial replication and distribution of the article with the strict proviso that no changes or edits are made and the original work is properly cited (including links to both the formal publication through the relevant DOI and the license). See: https://creativecommons.org/licenses/by-nc-nd/4.0/.

\section{References}

1. Lamelas J, Chen PC, Loor G, et al. Successful use of sternal-sparing minimally invasive surgery for proximal ascending aortic pathology. Ann Thorac Surg 2018;106:742-8.

2. Holzhey DM, Seeburger J, Misfeld M, et al. Learning minimally invasive mitral valve surgery: a cumulative sum sequential probability analysis of 3895 operations from a single high-volume center. Circulation 2013;128:483-91.

3. Doenst T, Diab M, Sponholz C, et al. The opportunities and limitations of minimally invasive cardiac surgery. Dtsch Arztebl Int 2017;114:777-84.

4. Lamelas J, Alnajar A. Recent advances in devices for minimally invasive aortic valve replacement. Expert Rev Med Devices 2020;17:201-8.

5. Sündermann SH, Sromicki J, Rodriguez Cetina Biefer H, et al. Mitral valve surgery: right lateral minithoracotomy or sternotomy? A systematic review and meta-analysis. J Thorac Cardiovasc Surg 2014;148:1989-1995.e4.

6. Alsarraj MK, Nellis JR, Vekstein AM, et al. Borrowing from adult cardiac surgeons-bringing congenital heart surgery up to speed in the minimally invasive era. Innovations (Phila) 2020;15:101-5.

7. Nellis JR, Daneshmand MA, Gaca JG, et al. A single center experience with minimally invasive approaches in congenital cardiac surgery. J Thorac Dis 2021;13:5818-25.

8. Aljanadi F, Toolan C, Theologou T, et al. Is obesity associated with poorer outcomes in patients undergoing minimally invasive mitral valve surgery? Eur J

Cardiothorac Surg 2021;59:187-91.

9. Mikus E, Calvi S, Brega C, et al. Minimally invasive aortic valve surgery in obese patients: Can the bigger afford the smaller? J Card Surg 2021;36:582-8.

10. Backer CL, Pasquali SK, Dearani JA. Improving national outcomes in congenital heart surgery: the time has come for regionalization of care. Circulation 2020;141:943-5.

11. Chang RK, Klitzner TS. Can regionalization decrease the number of deaths for children who undergo cardiac surgery? A theoretical analysis. Pediatrics 2002;109:173-81.

12. Austin JM, Derk JM, Pronovost PJ. An analysis of publicly reported pediatric heart surgery data and patient mortality implications. J Hosp Manag Health Policy 2018;2:50.

13. Welke KF, O'Brien SM, Peterson ED, et al. The complex relationship between pediatric cardiac surgical case volumes and mortality rates in a national clinical database. J Thorac Cardiovasc Surg 2009;137:1133-40.

14. Nakanishi K, Matsushita S, Kawasaki S, et al. Safety advantage of modified minimally invasive cardiac surgery for pediatric patients. Pediatr Cardiol 2013;34:525-9.

15. Del Nido PJ. Minimally invasive cardiac surgical procedures in children. Innovations (Phila) 2020;15:95-8.

16. Lee T, Weiss AJ, Williams EE, et al. The right axillary incision: a potential new standard of care for selected congenital heart surgery. Semin Thorac Cardiovasc Surg 2018;30:310-6.

17. Kale SB, Ramalingam S. Minimally invasive cardiac surgery without peripheral cannulation: a single centre experience. Heart Lung Circ 2019;28:1728-34.

18. Vida VL, Padalino MA, Boccuzzo G, et al. Minimally invasive operation for congenital heart disease: a sexdifferentiated approach. J Thorac Cardiovasc Surg 2009;138:933-6.

19. Nguyen K, Chin C, Lee DS, et al. The axillary incision: a cosmetic approach in congenital cardiac surgery. J Thorac Cardiovasc Surg 2007;134:1358-60.

20. Nicholson IA, Bichell DP, Bacha EA, et al. Minimal sternotomy approach for congenital heart operations. Ann Thorac Surg 2001;71:469-72.

21. Westfelt JN, Nordwall A. Thoracotomy and scoliosis. Spine (Phila Pa 1976) 1991;16:1124-5.

22. Bleiziffer S, Schreiber C, Burgkart R, et al. The influence of right anterolateral thoracotomy in prepubescent female patients on late breast development and on the incidence of scoliosis. J Thorac Cardiovasc Surg 2004;127:1474-80.

23. Yan L, Zhou ZC, Li HP, et al. Right vertical infra- 
axillary mini-incision for repair of simple congenital heart defects: a matched-pair analysis. Eur J Cardiothorac Surg 2013;43:136-41.

Cite this article as: Karangelis D, Androutsopoulou V, Tzifa A, Chalikias G, Tziakas D, Mitropoulos F, Mikroulis D. Minimally invasive cardiac surgery: in the pursuit to treat more and hurt less. J Thorac Dis 2021;13(11):6209-6213. doi: 10.21037/jtd21-1498
24. Agrawal H, Alkashkari W, Kenny D. Evolution of hybrid interventions for congenital heart disease. Expert Rev Cardiovasc Ther 2017;15:257-66. 